\title{
¿Francisco Carrasco, traductor del Pro Ligario de Cicerón? Alfredo Adolfo Camús y la ficción traductora
}

\author{
Francisco García Jurado \\ Universidad Complutense \\ pacogj@ucm.es
}

\begin{abstract}
Resumen: En 1857, el catedrático de literatura latina de la Universidad Central de Madrid, Alfredo Adolfo Camús (1817-1889), publica en el Semanario Pintoresco Español una supuesta traducción del Pro Ligario de Cicerón que dice haber encontrado en un viejo manuscrito cuando estaba a punto de ser destruido por un trapero. Asimismo, afirma Camús que se trata de una traducción debida a un personaje del siglo XVIII, Francisco Carrasco, Marqués de la Corona, de quien no se conocen otras versiones de clásicos. Tanto las circunstancias novelescas del hallazgo del manuscrito como la dudosa atribución hacen sospechar que estamos ante la ficción de un falso traductor y que, en realidad, el texto ciceroniano no es producto de una traducción directa, sino de la recomposición de una traducción previa del siglo XVIII.
\end{abstract}

Palabras clave: Pro Ligario; Cicerón; Alfredo Adolfo Camús; Rodrigo de Oviedo; ficción.

Francisco Carrasco, the translator of Cicero's Pro Ligario? Alfredo Adolfo Camús and translational fiction

\begin{abstract}
In 1857 Alfredo Adolfo Camús (1817-1889), Professor of Latin Literature at the Central University of Madrid, published in the Semanario Pintoresco Español a supposed translation of Cicero's Pro Ligarius. Camús tells us that he had found it in an old manuscript when it was about to be destroyed by a ragman and argues that it is a translation by a character of the eighteenth Century, Francisco Carrasco, Marqués de la Corona, whose other versions of classics are not known by us. Both fictional circumstances, namely, the find of the manuscript as well as its doubtful attribution suggest us that this is not but a false translation and that, in fact, Cicero's text does not come from a direct version, but the remake of a previous text written in the eighteenth Century.

Keywords: Pro Ligario; Cicero; Alfredo Adolfo Camús; Rodrigo de Oviedo; fiction.

》) García Jurado, Francisco. 2016. “¿Francisco Carrasco, traductor del Pro Ligario de Cicerón? Alfredo Adolfo Camús y la ficción traductora”. Quaderns de Filologia: Estudis Lingüistics XXI: 127-146. doi: 10.7203/qfilologia.21.9316
\end{abstract}





\section{Introducción}

Menéndez Pelayo recoge en el tomo II de su Bibliografía Hispano Latina clásica la siguiente noticia relativa a una traducción de Cicerón:

CCLIV. CARRASCO, Francisco, Marqués de la Corona. (En Semanario Pintoresco).- Madrid, 1857.

Oración de Cicerón a César por Ligario, traducida por D. Francisco Carrasco, marqués de la Corona, oidor de la Audiencia de Zaragoza y fiscal del Supremo Consejo de Hacienda en tiempo de Carlos III.

Semanario Pintoresco Español. Tomo correspondiente al año de 1857. Págs. 37-40.

Del hallazgo de esta traducción da noticia una carta preliminar del Dr. D. Alfredo Adolfo Camús al director del Semanario (págs. 30-31), la cual reproducimos íntegra, siguiendo nuestro propósito de salvar los opúsculos dispersos de aquel benemérito humanista e inolvidable maestro. (Menéndez Pelayo, 1952: 405-406)

Por lo que nos deja entrever la noticia bibliográfica, el profesor Alfredo Adolfo Camús (1817-1889), uno de los maestros más queridos que Menéndez Pelayo tuvo en la Universidad de Madrid, había publicado en el Semanario pintoresco español ${ }^{1}$ dos entregas acerca de una traducción desconocida del discurso ciceroniano en defensa de Quinto Ligario a cargo de un notable personaje del siglo XVIII, Francisco Carrasco (1715-1791), letrado y jurista que obtuvo el título de Marqués de la Corona ${ }^{2}$. Menéndez Pelayo tan sólo reproduce a continuación el texto donde Camús expone las circunstancias del hallazgo del manuscrito, en aras a conservar los testimonios escritos de su inolvidable maestro. Omite, sin embargo, el texto de la traducción ciceroniana y no hace jui-

\footnotetext{
* Este trabajo se inscribe en el proyecto de investigación FFI2013-41976, "Historiografía de la literatura grecolatina en España 3: el 'Legado Alfredo Adolfo Camús' en la Biblioteca Histórica Marqués de Valdecilla” (2014-2016), financiado por el Ministerio de Economía y Competitividad. Agradezco a los dos informantes desconocidos del original su atenta lectura y puntos de vista.

${ }^{1}$ Camús, 1857a y 1857b. El Semanario Pintoresco Español es una publicación fundada por Mesonero Romanos en 1836 y definida por su carácter curioso y costumbrista, propio de la primera mitad del siglo XIX (Simón Díaz, 1846).

${ }^{2}$ Esta figura histórica, no tan conocida como la de otros contemporáneos suyos, ha sido bien estudiada por Delgado Barrado, 2005, partiendo del trabajo ya clásico de Moxó y Ortiz de Villajos, 1959.
} 
cio alguno sobre ella. Es entonces, una vez iniciada la lectura del texto de Camús, cuando comienzan a aflorar las dudas acerca de la veracidad del documento, pues las dramáticas circunstancias del hallazgo de los papeles donde se encontraba tal traducción son propiamente novelescas:

Hace algún tiempo que en cierto puesto de esta corte, en donde solían entrar los libros a carretadas para volver a salir en pocos días a espuertas y por arrobas, vi vender para cartón una abundante colección de manuscritos de la pertenencia de un varón insigne, una de las glorias de la magistratura y de la administración española, D. FRANCISCO CARRASCO, marqués de la Corona. Allí descubrí en revuelta confusión dictámenes fiscales, informes evacuados en voluminosos in folios, muchos de ellos de la propia mano del ilustre Marqués, pues su firma y rúbrica con frecuencia repetidas al pie de muchos documentos de interés público, de minutas de cartas a varios ministros del reinado del Señor Carlos III, no dejaban lugar a duda sobre el particular.

Mientras cargaban los mozos aquel inmenso fárrago de manuscritos ya pesados y vendidos, fárrago que representaba tantas noches de vigilia, tantos años de trabajo consagrados al servicio de la patria, ya en importantes cargos judiciales, ya en los consejos supremos del Soberano, hubo de anublárseme el alma y entristecérseme el corazón.- Si hubiera visto quemar los huesos del noble repúblico para hacer betún de botas, no me hubiera afligido tan profundamente como con esa profanación de sus escritos comprados y vendidos para hacer cartón. Salíame de casa del librero para irme a meditar a mis anchas sobre la ingratitud de los hombres y la indiferencia de las naciones, cuando al pasar por la puerta tropecé con el robusto astur que cargaba con las últimas espuertas de papeles; y entonces, como si el ánima del muerto agradecida de mi piadosa aflicción (las almas de los muertos han sido siempre más propensas a la gratitud que las de los vivos), deseando quizás dejarme una fineza o un recuerdo, lo hiciera de intento, se desprendió del copete de la espuerta un cuaderno doblado en dos. Como ya el mozo iba trotando por la calle, alarguéselo al fabricante de cartones, que estaba pagando en calderilla al librero el importe de su compra, de la que parecía estar satisfecho.-Caballero, le dije, esto se ha caído del último viaje.-Gracias, me contestó contando los cuartos, eso no vale nada.- iQue no vale nada! repetí indignado al reconocer la letra.—_Sabe V. que es un autógrafo del marqués de la Corona, oidor de la Audiencia de Zaragoza, fiscal del Supremo Consejo de Hacienda en tiempo de...?-No prosiga V., me interrumpió diciendo el honrado menestral; no soy más que un 
fabricante de cartones, y no me ocupo de leer los papeles que van a parar a mis tinas, sino del peso de la pasta que contienen; pero ya que se ha caído, y a V. le gusta, quédeselo, y buen provecho le haga.-Mucho estimo, caballero, contesté, su fina atención; pero...-Ya entiendo, dijo riendo aquel buen hombre, no se atreve $\mathrm{V}$. a recibir de quien no conoce, un regalo de tanto valor. Y viendo que se me iban subiendo los colores al rostro, añadió, lanzando una franca y estrepitosa carcajada: eche usted tres piezas de a dos cuartos en ese montón para completar la cuenta, y hago un negocio loco.-Saqué mis seis cuartos, que puse sobre el mostrador, apreté con efusión la mano del fabricante de cartones y me salí a devorar mi manuscrito, mío por la cantidad de 24 maravedís, un cuarto más de lo que debió costar el papel en blanco, porque el cuaderno tiene cabales seis pliegos de marca mayor.

El manuscrito salvado como por milagro de los reactivos de la fábrica de cartones era nada menos que una traducción hecha de mano maestra, como usted verá, de la célebre "Oración de Cicerón a César por Ligario". (Camús, apud Menéndez Pelayo, 1952: 407-408)

Por otra parte, al supuesto autor de la versión ciceroniana, Francisco Carrasco, no se le conoce como traductor de clásicos grecolatinos. Todo apunta, por tanto, a sospechar que la traducción que Camús nos ofrece del Pro Ligario en el Semanario pintoresco es, en realidad, el resultado de la adaptación moderna de un texto más antiguo y que se ha recurrido a la impostura ( $o$, en términos más suaves, a la broma literaria) de un traductor ficticio para justificar su propia versión indirecta. El referido tono dramático de las circunstancias del hallazgo del manuscrito sería suficiente para cualquier lector avisado a la hora de detectar la superchería, pero el paso del tiempo puede desdibujar el carácter de esta ficción. De hecho, Menéndez Pelayo recoge la noticia de la supuesta traducción de Francisco Carrasco como si de una información fidedigna se tratara, sin ser contrastada (probablemente ni se le hubiera pasado por la cabeza la posibilidad de que su entrañable maestro estuviera creando una impostura $)^{3}$. Habida cuenta, por tanto, de que estamos ante un hecho ficticio, debemos dilucidar cuál fue la traducción de la que partió Camús para elaborar esta nueva versión del discurso. A priori, cabría pensar en dos posibilidades básicas:

\footnotetext{
${ }^{3}$ El librero Palau y Dulcet refiere igualmente el episodio de este hallazgo en sus memorias (Palau y Dulcet, 1935: 284).
} 
- que Camús hubiera elaborado su versión ficticia a partir de una traducción francesa

- que hubiera partido de una antigua versión hispana que, a tenor de los gustos humanistas e ilustrados de Camús, fuera bien del siglo XVI, bien del siglo XVIII

Descarté pronto la primera posibilidad al ver, por ejemplo, que la traducción francesa más popular de este discurso, disponible en la colección Nisard ${ }^{4}$, no ofrecía mayores paralelismos con la española y al observar, por su parte, que a la versión española no se le habían escapado posibles galicismos. Decantándome, pues, por la hipótesis de que el texto de partida fuera una traducción hispana, recurrí a la que Camús hubiera podido tener más a mano y que no era otra que la versión de Rodrigo de Oviedo (1746-después de 1816) publicada por Antonio de Sancha en 1783. Fue en esta versión donde, tras el oportuno cotejo, encontré partes prácticamente iguales con respecto al texto de Camús y otras que diferían de manera significativa. Camús, que sentía una rendida admiración por el autor latino, al crear esta ficción traductora aúna su pasión ciceroniana con la del gusto por las antiguas traducciones de los clásicos. Que la supuesta versión ciceroniana se sitúe históricamente en el siglo XVIII responde también al éxito del que el autor latino gozó durante este siglo ${ }^{5}$.

El propósito de este trabajo es analizar, primero, cuáles son las características de esta reescritura de Camús a partir de la de Rodrigo de Oviedo y, ya después, analizar sus posibles intenciones al llevar a cabo tal reescritura.

\section{La refección de la traducción ciceroniana de Rodrigo de Oviedo}

Profesor de latín en los Reales Estudios de San Isidro, Rodrigo de Oviedo es uno de los traductores españoles más importantes del siglo XVIII. Sus Oraciones Escogidas de Cicerón fueron publicadas primeramente por Antonio de Sancha en Madrid ${ }^{6}$. Se trata de una edición bilingüe que

\footnotetext{
4 "Plaidoyer pour Q. Ligarius" (Nisard, 1840: 250-259).

${ }^{5}$ Aradra Sánchez (2011) nos ofrece un buen panorama al respecto.

${ }^{6}$ Cicerón, 1789.
} 
responde perfectamente a los propósitos ilustrados de poner a disposición del público instruido la obra de Cicerón dotada de una fiel y clara versión española. De manera significativa, en la relación de fichas que Menéndez Pelayo nos ofrece sobre Cicerón, la traducción ciceroniana de Rodrigo de Oviedo precede a la supuesta versión del Pro Ligario hecha por Francisco Carrasco. Una comparación a simple vista entre ambos textos revela paralelismos y singulares divergencias. Veamos, como muestra significativa, el comienzo y el final de ambas traducciones. Señalo mediante cursiva la parte del texto de Camús que aparece claramente inspirada por la traducción de Rodrigo de Oviedo:

\begin{tabular}{|c|c|}
\hline Texto de Rodrigo de Oviedo & exto de Camús \\
\hline$(\mathrm{Cis}$ & \\
\hline $\begin{array}{l}\text { EXORDIO. Con una acusación nueva, y } \\
\text { hasta el día de hoy nunca oída, fue a ti, } \\
\text { o C. César, mi pariente Q. Tuberón, es a } \\
\text { saber, de que Q. Ligario se había hallado } \\
\text { en África, y el caso es que se atrevió a } \\
\text { confesarlo C. Pansa, sujeto de sobresa- } \\
\text { liente ingenio, confiado acaso en la fami- } \\
\text { liaridad, que contigo tiene. Y así no sé a } \\
\text { qué parte volverme. Porque en el supues- } \\
\text { to de que tú no habías sabido esto por ti, } \\
\text { ni podido oírlo al otro, venía aparejado } \\
\text { el aprovecharme de esta tu ignorancia } \\
\text { para salvar a un infeliz. Pero ya que por } \\
\text { el cuidado del enemigo se ha descubierto } \\
\text { lo que estaba oculto, juzgo por preciso el } \\
\text { confesarlo; y especialmente cuando mi } \\
\text { amigo C. Pansa ha cerrado la puerta con } \\
\text { su confesión a este recurso, y así deján- } \\
\text { donos de disputas, todo mi discurso se ha } \\
\text { de dirigir a tu misericordia, que conservó } \\
\text { a muchísimos, que consiguieron de ti no } \\
\text { la absolución de culpa, sino el perdón del } \\
\text { yerro. [...] }\end{array}$ & $\begin{array}{l}\text { EXORDIO. Un nuevo delito y hasta hoy } \\
\text { jamás oído, Cayo César, te ha delatado mi } \\
\text { pariente Quinto Tuberón: que Quinto Li- } \\
\text { gario estuvo en África, y halló que Cayo } \\
\text { Pansa Varón de superior talento, confiado } \\
\text { acaso en su amistad se ha atrevido en la } \\
\text { defensa que ha hecho por Ligario a con- } \\
\text { fesar este delito. No sé yo qué rumbo } \\
\text { tomar; prevenido venía, una vez que ni } \\
\text { podía [s] saberlo por ti mismo, ni haberlo } \\
\text { oído por otra parte, a aprovecharme de tu } \\
\text { ignorancia para redimir a un infeliz; pero } \\
\text { pues la diligencia del contario ha descu- } \\
\text { bierto este secreto, tengo por más acerta- } \\
\text { do el confesarlo, mayormente no habién- } \\
\text { dome dejado arbitrio para otra cosa mi } \\
\text { estrecho amigo Cayo Pansa, y omitiendo } \\
\text { los debates se encaminará toda mi ora- } \\
\text { ción a tu misericordia, que es a la que } \\
\text { deben su conservación muchisimos que } \\
\text { han logrado de ti, no que les absuelvas } \\
\text { de culpa, sino que les perdones su yerro. } \\
\text { [...] }\end{array}$ \\
\hline
\end{tabular}




\begin{tabular}{|c|c|}
\hline Texto de Rodrigo de Oviedo & Texto de Camús \\
\hline (Cic. Lig. 37-38) & \\
\hline $\begin{array}{l}\text { EPíloGO. [...] Lo mismo que poco ha hi- } \\
\text { ciste en la curia en la restitución del muy } \\
\text { noble, y esclarecido M. Marcelo, hazlo } \\
\text { ahora en el foro con estos tan buenos } \\
\text { hermanos, y tan estimados de todo este } \\
\text { concurso. Así como concediste la restitu- } \\
\text { ción de aquel a los respetos del senado, } \\
\text { así concede la de éste a los del pueblo, } \\
\text { a quien siempre has deseado muchísimo } \\
\text { complacer. Y si aquel día fue para ti glo- } \\
\text { riosísimo, y muy grato al pueblo romano, } \\
\text { te ruego, no dudes en procurar una gloria } \\
\text { semejante a aquéllas las más veces que } \\
\text { puedas. No hay cosa tan del agrado del } \\
\text { pueblo, como la bondad: ninguna de las } \\
\text { muchas virtudes, que te adornan, es más } \\
\text { agradable, ni más de admiración que tu } \\
\text { misericordia: porque en nada se acercan } \\
\text { más los hombres a los dioses, que salvan- } \\
\text { do a otros hombres. La mayor grandeza } \\
\text { de tu fortuna es el poder conservar a mu- } \\
\text { chísimos, y lo mejor que tiene tu natural, } \\
\text { es el quererlo hacer. La causa pide acaso } \\
\text { un discurso más largo; mas tu condición } \\
\text { le pide sin duda más breve. Por lo cual, } \\
\text { teniendo por más útil que te hables tú a } \\
\text { ti mismo, que no te hable yo, ni ningún } \\
\text { otro, pondré ya fin a mi oración. Sólo te } \\
\text { advertiré, que con salvar a éste, que está } \\
\text { ausente, salvarás a todos los que aquí se } \\
\text { hallan presentes. }\end{array}$ & $\begin{array}{l}\text { PERORACIÓN. [...] La gracia que poco } \\
\text { ha hiciste el Senado de restituirle al muy } \\
\text { noble y esclarecido Marcelo, hazla ahora } \\
\text { al pueblo restituyéndole estos hermanos } \\
\text { que tanto aprecia y ama. } \\
\text { (Falta una frase) } \\
\text { Si aquel día fue para ti tan glorioso y tan } \\
\text { alegre para el pueblo romano, no excu- } \\
\text { ses, te pido, buscar repetidas veces oca- } \\
\text { siones de tanta alabanza y gloria. Ningu- } \\
\text { na cosa es tan amada del público como } \\
\text { la bondad. De todas las muchas virtudes, } \\
\text { ninguna es tan grata y admirable como } \\
\text { tu misericordia. Los hombres en nada se } \\
\text { acercan tanto a los Dioses como en dar } \\
\text { la vida a los demás hombres. Nada hay } \\
\text { en tu grandeza mayor que poder, y nada } \\
\text { en tu índole, mejor que querer conservar } \\
\text { la vida y fortuna a tantos. Oración más } \\
\text { larga pediría acaso esta causa, pero para } \\
\text { tu ánimo generoso correspondía ser más } \\
\text { breve. Doila ya fin, porque contemplo } \\
\text { más útil que tú hables contigo mismo, } \\
\text { que el que yo ni cualquiera otro te ha- } \\
\text { blemos: solamente te advierto ya, que si } \\
\text { perdonases al ausente, darás vida a cuan- } \\
\text { tos están en tu presencia. }\end{array}$ \\
\hline
\end{tabular}

Por lo que nos dejan entrever las palabras en cursiva, observamos que Camús ha partido claramente del texto de Rodrigo de Oviedo, si bien se ha cuidado mucho de reducir tales coincidencias al mínimo posible mediante una hábil reescritura. El método de reescritura no se limita únicamente al ámbito del léxico y las expresiones. Si nos fijamos en la primera frase, observaremos que Camús ha reescrito la traducción de Rodrigo de Oviedo no sólo variando palabras, sino también el orden 
mismo de tales palabras, de manera que, paradójicamente, ha convertido su supuesta traducción en más literal que la del propio Rodrigo de Oviedo con respecto al texto latino?:

\begin{tabular}{|l|l|}
\hline Cicerón & Camús \\
\hline Nouum crimen, C. Caesar, et ante hunc & Un nuevo delito y hasta hoy jamás oído, \\
diem non auditum propinquus meus ad & Cayo César, te ha delatado mi pariente \\
te Q. Tubero detulit, Q. Ligarium in & Quinto Tuberón: que Quinto Ligario estu- \\
Africa fuisse, idque C. Pansa, praestanti & vo en África, y halló que Cayo Pansa Va- \\
vir ingenio, fretus fortasse familiaritate & rón de superior talento, confiado acaso en \\
ea quae est ei tecum, ausus est confiteri. & $\begin{array}{l}\text { su amistad se ha atrevido en la defensa que } \\
\text { ha hecho por Ligario a confesar este delito. }\end{array}$ \\
(Cic. Lig. 1$)$ &
\end{tabular}

El mismo fenómeno puede observarse de manera muy particular en esta otra frase que encontramos ya al final del discurso, y que en este caso vamos a cotejar a partir de los tres textos posibles:

\begin{tabular}{|l|l|l|}
\hline Cicerón & Rodrigo de Oviedo & Camus \\
\hline Nihil habet nec fortuna tua & La mayor grandeza de tu & Nada hay en tu grandeza \\
maius quam ut possis, nec & fortuna es el poder con- & mayor que poder, y nada \\
natura melius quam ut ve- & servar a muchísimos, y lo & en tu índole, mejor que \\
lis servare quam plurimos & mejor que tiene tu natural, & querer conservar la vida y \\
(Cic. Lig. 38) & es el quererlo hacer. & fortuna a tantos. \\
\hline
\end{tabular}

Se ve claramente cómo el comienzo de la frase por parte de Camús ("nada hay en tu grandeza [...]") supone una refección del texto de Rodrigo de Oviedo a partir de la palabra "grandeza" ("la mayor grandeza de tu fortuna [...]"), si bien las palabras se reordenan aprovechando que el texto latino comienza con el término nihil; a continuación, el texto de Camús se vuelve prácticamente literal con respecto al latino, reservándose como única licencia la inclusión de la palabra "fortuna" (inicialmente aplicada a César) en un contexto bien distinto, dado que ahora la vemos coordinada con "la vida" de los condenados por él:

\footnotetext{
${ }^{7}$ Consideramos que el texto latino más cercano del que disponía Camús era el que estaba enfrentado a la propia traducción de Rodrigo de Oviedo. Es por ello por lo que citaremos este texto, si bien lo hemos confrontado siempre con la moderna edición oxoniense de Clark (Cicerón, 1970).
} 
[...] que poder, y nada en tu índole, mejor que querer conservar la vida $y$ fortuna a tantos

[...] ut possis, nec natura melius quam ut velis servare quam plurimos

De esta forma, observamos que Camús ha partido del texto de Rodrigo de Oviedo (ya hemos visto que la palabra "grandeza", introducida por éste para reforzar el comparativo maius, es clave a este respecto) intentado compaginar las variaciones introducidas en tal versión con una buscada literalidad respecto al propio texto latino de Cicerón. A partir de los pasajes inicial y final ya citados, es posible categorizar cuatro criterios seguidos por Camús a la hora de crear esta nueva versión:

- Se cambia de categoría gramatical algunas palabras tomadas directamente de Rodrigo de Oviedo, como es el caso del sustantivo "perdón" en "perdón de su yerro" (Oviedo) reconvertido en el verbo "perdonar" dentro de la expresión "que perdonen su yerro" (Camús) o, inversamente, el verbo "conservar" en "que conservó a muchísimos" (Oviedo) reconvertido en el sustantivo "conservación" en "la que deben su conservación muchísimos" (Camús).

- Se recurre a variantes léxicas, como vemos en el cambio del término "acusación" (Oviedo) por "delito" (Camús) para traducir crimen, o "sujeto de sobresaliente ingenio" (Oviedo), ahora reescrito como "varón de superior talento" (Camús) para traducir praestanti vir ingenio.

- Se cambia el orden de los elementos de la frase, en muchos casos devolviendo el texto traducido a cierta literalidad con respecto al texto latino, como ocurre con la primera frase del discurso (Cic. Lig. 1) o la frase del epílogo (Cic. Lig. 38).

- Cabe, asimismo, hacer notar algunos raros añadidos que hace Camús, como cuando inserta un adjetivo en el sintagma "mi estrecho amigo Cayo Pansa" donde Rodrigo de Oviedo traduce tan sólo "mi amigo C. Pansa" a partir del texto meus necessarius Pansa.

Tales características definen la refección que Camús hace a lo largo de todo el discurso, incluso corrigiendo alguna equivocación de Rodrigo de Oviedo ("Entre tanto llegó a Italia P. Acio Varo" [Cic. Lig. 2]), 
que Camús reescribe correctamente ("A este tiempo Accio Varo [...] llegó a Útica”). No por resultar obvias deben preterirse las partes del texto de Rodrigo de Oviedo que aparecen transcritas como tales en la nueva versión de Camús. Podríamos pensar, haciendo de abogados del diablo, que los textos coincidentes pudieran responder a idénticas soluciones de traducción. Sin embargo, las soluciones coincidentes son tantas y tan significativas que no se pueden atribuir a la mera casualidad.

Por lo demás, tanto Rodrigo de Oviedo como Camús dividen el discurso en diferentes partes, según lo prescrito por la Oratoria. También en este particular Camús coincide en lo esencial con Rodrigo de Oviedo, pero ha querido establecer algunas diferencias con respecto al humanista del siglo XVIII:

\begin{tabular}{|l|l|}
\hline Rodrigo de Oviedo & Camús \\
\hline Exordio (Cic. Lig. 1-4) & Exordio (Cic. Lig. 1-2) \\
\hline & Narración (Cic. Lig. 2-5) \\
\hline Proposición (Cic. Lig. 5) & \\
\hline Confirmación (Cic. Lig. 6-30) & Contención (Cic. Lig. 6-30) \\
\hline Epílogo (Cic. Lig. 30-38) & Peroración (Cic. Lig. 31-38) \\
\hline
\end{tabular}

Partiendo del hecho de que en la práctica no hay unanimidad a la hora de categorizar y establecer dónde comienzan y terminan las distintas partes del discurso, observamos que la diferencia básica entre ambas ordenaciones está en la segunda de las partes determinada por cada autor. El Exordio del discurso es para Rodrigo de Oviedo más extenso que el que establece Camús, y mientras el primero hace que al Exordio le siga la Proposición, Camús, por su parte, decide que sea la Narración. En lo que concierne a la tercera parte del discurso, Camús ha preferido recurrir al término "Contención" para referirse a lo que Rodrigo de Oviedo denomina "Confirmación". Sabido es que, desde antiguo, el término "Contención" englobaba la "Confirmación" y la "Refutación". Camús procede, por tanto, con conocimiento de causa. Conviene recordar que

\footnotetext{
${ }^{8}$ Gregorio Mayans lo explica perfectamente su Retórica: "El rechazamiento es como un apéndice o añadidura de la confirmación; pues quita los reparillos, que hay contra la razón, para que no se tropiece en ellos, ni embaracen el curso de la persuasión. Por eso los antiguos, juntando la confirmación y el rechazamiento, llamaron a una, y otra,
} 
éste había sido profesor de Retórica y Poética en la Universidad Central de Madrid antes de ganar la cátedra de Literatura latina en 1848, y que compiló tres manuales muy difundidos sobre tales materias. De manera particular, en el manual donde resumió y compiló la Retórica de Hugo Blair y la Poética de Sánchez Barbero (Camús, 1847: 107) se establecen seis partes posibles en el discurso: 1. ${ }^{a}$ Exordio o Introducción; 2. ${ }^{a}$ Proposición y División: $3 .^{\mathrm{a}}$ Narración o Exposición; 4. ${ }^{\mathrm{a}}$ Pruebas; $5{ }^{\mathrm{a}}$ la Parte patética; $6 .{ }^{a}$ Conclusión.

\section{Posible intención del discurso: un Cicerón "liberal"}

Según hemos intentado mostrar, Camús crea una ingeniosa impostura a la hora de reescribir la traducción dieciochesca de un discurso de $\mathrm{Ci}$ cerón, el Pro Ligario, a la luz del texto latino. Asimismo, finge haber encontrado tal traducción ficticia en un manuscrito cuya autoría atribuye al notable jurista Francisco Carrasco, a quien considera "un varón insigne, una de las glorias de la magistratura y de la administración española". No nos parece que esta atribución sea inocente, sobre todo tratándose de uno de los ilustrados que quiso llevar a cabo un intento de desamortización de los bienes eclesiásticos en tiempos de Carlos III' Cuando Camús publica en 1857 la supuesta traducción dieciochesca del Pro Ligario cabría considerar a Carrasco como un precursor de la propia desamortización que en 1855 había llevado a cabo Pascual Madoz (1806-1870) con los gobiernos de los generales Espartero y O’Donnell. El asunto, pues, revestía actualidad y no era ajeno al trasiego de las luchas políticas entre liberales y conservadores, que podían hacer recordar las propias luchas civiles entre Pompeyo y César, según cuenta el propio Cicerón. De esta forma, si nuestro desvelamiento de la impostura ya es, como tal, un resultado notable para este trabajo de investigación, queremos plantear ahora cuáles pudieron ser, más allá de una ingeniosa broma filológica, las razones últimas que llevaron a Camús a realizar tal impostura. En este sentido, cabe plantear una sutil relación entre la

contención, o contienda; porque son las dos partes sobre que se contiende; y contendor, al abogado." (Mayans, 1786: 280).

${ }^{9}$ Para un primer acercamiento al asunto puede consultarse Friera Álvarez (2007: 20), que adscribe a Francisco Carrasco junto a Campomanes y Olavide por una concepción aún señorial del derecho de propiedad frente a otros ilustrados más avanzados a este respecto, como Floridablanca y Jovellanos. 
fecha de publicación de esta supuesta versión ciceroniana (1857), la atribución específica a un personaje tan señalado del reinado de Carlos III, Francisco Carrasco (si bien no tan conocido como Campomanes u Olavide), y el propio hecho de que el discurso elegido haya sido el de la defensa de Quinto Ligario, donde Cicerón implora a César el perdón para su defendido, dado que había estado en el lado de su rival Pompeyo. Para ello, conviene que leamos con detenimiento algunos pasajes entresacados de la emotiva semblanza que de Cicerón y su discurso hace el propio Camús dentro del artículo introductorio, tras haber dado cuenta de las novelescas circunstancias del hallazgo:

Me parece que ni Plutarco, ni Middleton han sabido poner suficientemente de relieve el rasgo más característico de aquella alma honrada y generosa. Colocado, por desgracia, en medio de la lucha ardiente y sangrienta de los partidos extremos que se disputan, no la gloria de salvar la patria, sino la lucrativa administración del mundo vencido, intenta Marco Tulio un imposible; cuando Roma se divide en dos bandos acaudillados por César y por Pompeyo, quiere el virtuoso ciudadano ser del partido de la patria [...] (Camús, apud Menéndez Pelayo, 1952: 409-410).

Es significativo que Camús se refiera, además de a la imprescindible biografía ciceroniana a cargo de Plutarco, al no menos fundamental Conyers Middleton (1683-1750), autor de una famosa Vida de Cicerón publicada en Inglaterra y luego vertida al español por Nicolás de Azara (1730-1804) (la primera edición es de 1790 y la segunda de 1804). Middleton nos presenta a Ligario como un ferviente defensor de la libertad de su patria, motivo por el cual Cicerón no dudó en defenderlo:

El gran celo con que Ligario se había distinguido por la libertad de la patria era la causa verdadera por que Cicerón se empeñó en defenderle; y por el mismo motivo César estaba tan mal dispuesto a concederle la gracia (Middleton, 1804: 201).

Resulta singular y, al mismo tiempo, paradójico el hecho de que una obra escrita por un autor partidario del parlamentarismo y contrario a las intromisiones del monarca en la política (Sánchez Espinosa, 1999: 285) termine convirtiéndose en uno de los libros más bellos y representativos del absolutismo ilustrado de Carlos III (de hecho, el gasto de la edición corrió "a cuenta del rey" [Sánchez Espinosa, 1999: 286]). No obstante, 
la versión de Azara hizo posible que Cicerón se convirtiera "en modelo de actuación a los hombres de letras españoles que colaboraron con el poder en la tarea de las reformas" durante los años finales del reinado de Carlos III (Sánchez Espinosa, 1999: 293). Es aquí donde podemos entender las razones por las que Camús quiso atribuir la supuesta versión de Cicerón a uno de aquellos ilustrados y observar cómo en la biografía de Middleton pueden hallarse las bases para fundamentar la visión liberal que Camús tiene de Cicerón, fundamentalmente como enemigo de la tiranía ${ }^{10}$. Además de Cicerón, los otros dos personajes fundamentales del momento son Pompeyo y César, a quienes describe de manera elocuente:

Hay, sin embargo, horas tan aciagas para las naciones, en que no es a nadie lícito permanecer alejado de la arena fratricida. Entre Pompeyo, capitán afortunado, a quien la caprichosa victoria se ha empeñado en coronar de laureles, de intención recta pero limitada, amando la libertad a su manera, vano y sensible en demasía a las lisonjas de sus parciales que lo dominan como a un niño; y Julio César, descendiente de Venus por Eneas, padre del pueblo romano según las tradiciones poéticas de su abolengo, versado en las letras como un griego del tiempo de Pericles, más disoluto que Alcibiades, adorado de las mujeres por su afeminada elegancia, su prodigalidad y lujo sin freno, querido del pueblo, que piensa reconocer en sus elocuentes palabras el eco de la voz de Graco, admirado del soldado que primero respeta en él al sobrino de Mario, vencedor de los cimbrios, y luego al infatigable caudillo, al hábil negociador, al pacificador de las Galias, al perfumado Pontífice, débil, al parecer, de cuerpo y de ánimo, que se pasea con la túnica negligentemente desceñida por los pórticos del Campo de Marte o tendido sobre los pulvinares de su litera de marfil como una mujer por la vía Apia; pero que en los campamentos ciñe su cabeza calva con la galea y viste el sagum como un centurión, esgrime la espada como un gladiador, arroja el venablo como un Sármata, maneja la honda como un Balear, salva los torrentes como un Picto, soporta el frío y las nieves como un Germano, el hambre y la sed como el último de sus legionarios; [...] (Camús, apud Menéndez Pelayo, 1952: 410-412).

\footnotetext{
${ }^{10}$ En el "Legado Camús" depositado en la Biblioteca Histórica Marqués de Valdecilla (Universidad Complutense) se conserva un ejemplar de la segunda edición española (tomo IV) y otro de la edición francesa de 1743.
} 
La frase inicial de este pasaje ("Hay, sin embargo, horas tan aciagas para las naciones, en que no es a nadie lícito permanecer alejado de la arena fratricida") bien podría aplicarse tanto a la convulsa Roma republicana como a la agitada España del XIX. Camús, tan dado en sus clases de la Universidad Central a comparar aspectos de la Antigüedad con su propia realidad social y política, no pudo evitar sentirse tentado por hacerse eco, mediante un episodio notable de la Historia de Roma, de aquello que estaba sucediendo en su misma época. De hecho, un año más tarde, también publica una extensa carta abierta ( 5 de junio de 1858) que dedica a su amigo y antiguo discípulo Emilio Castelar. En esta carta incluye, reconociéndola como propia, la traducción de la conocida como "Homilía" o "Carta a los jóvenes" compuesta por San Basilio Magno (Camús, 2015). Esta antigua obra, que invitaba a incluir el estudio de los autores paganos en la formación de los jóvenes cristianos, se ponía ahora en relación con el problema que se vivía durante la segunda mitad del siglo XIX, cuando un eclesiástico francés, de carácter ultraconservador, conocido como el abate Gaume acusó a las letras paganas de ser las causantes de los males de la modernidad. En realidad, con este ataque a los clásicos paganos se arremetía contra el desarrollo de la propia enseñanza pública, no en vano relacionada con el control estatal frente a la supuesta libertad de la enseñanza privada y religiosa. El asunto, espinoso como pocos, llega hasta nuestros propios días. De esta forma, mediante el texto de San Basilio Magno, Camús estaba buscando la actualidad de un texto antiguo para arrojar luz sobre un problema de su tiempo. Consideramos que el recurso al texto de $\mathrm{Ci}$ cerón tiene que ver también con una actualización de carácter semejante. De hecho, el delicado y rocambolesco momento político vivido en España entre 1857 y 1858 nos permite establecer una analogía, salvadas las muchas distancias, entre el ambicioso César y Pompeyo, que ama la libertad "a su manera", con respecto a las facciones políticas encabezadas por Ramón María Narváez y Campos (1800-1868) y Leopoldo O'Donnell (1809-1867). Tanto en el caso de los antiguos como en el de los modernos, los personajes históricos representan posturas irreconciliables encarnadas por sendos generales. En el momento en que Camús publica su trabajo, la Unión Liberal de O’Donnell había caído en desgracia y se vivía un momento de involución política por parte de Narváez. Las analogías entre liberales y conservadores con respecto a las facciones pompeyana y cesariana, si bien no resultan unívocas, 
están servidas. Por lo que vemos en algún que otro libelo publicado durante el decenio de los años cincuenta del siglo XIX, la analogía entre Narváez y César hasta podía llegar a ser un lugar común. Así aparece en un opúsculo donde el ácido escritor y periodista Juan Martínez Villergas (1816-1894) compara, un tanto a la manera de Plutarco, las vidas de los generales Espartero y Narváez. En cierto momento, podemos leer el siguiente parangón entre el despotismo de César, Napoleón y Narváez:

El despotismo de un César o un Napoleón, era una carga pesada para el pueblo, el de Narváez era una carga afrentosa (Martínez Villergas, 1851: 157).

Con respecto a Pompeyo, a quien Camús califica "vano y sensible en demasía a las lisonjas de sus parciales que lo dominan como a un niño”, el parangón con O’Donnell bien podría basarse en esta afición a las lisonjas o adulaciones, como vemos en este curioso texto de la época escrito por el periodista y dramaturgo Ildefonso Antonio Bermejo (1820-1892), donde se compara irónicamente al militar español con varios personajes de la Antigüedad:

Con todas estas cosas se dio a O’Donnell el título de duque de Tetuán, y a otros generales dictados pomposos. Los diarios vicalvaristas pedían para O'Donnell un puesto superior al que conquistaron Metelo, Mario, César, Pompeyo, Sertorio, Antonio, Marco Aurelio, Alejandro Severo y otros capitanes de idéntico renombre; [...] (Bermejo, 1872: 474).

Ante las desmesuras de poder y el amor a la autocracia cesariana $\mathrm{Ca}$ mús recurre a Cicerón, en cuyo retrato cabe adivinarse la impronta de Middleton cuando se califica al gran orador de "sagacísimo" y último garante de las viejas libertades republicanas:

Pero César, adornado de tantas cualidades esclarecidas, es un monstruo de insaciable ambición; su portentosa superioridad en vicios y virtudes es un pedestal tan alto en medio del pueblo romano, es tan simpático su carácter aún a los ojos de sus enemigos, que el sagacísimo Cicerón, defensor desinteresado de las venerandas leyes de Roma, custodio ferviente de la libertad republicana, comprendió muy luego que en la persona de Julio se escondían, no cien Marios, como había anunciado Sila antes de morir, sino la humillación del Senado, el aniquilamiento de las franquicias del pueblo y la esclavitud para todos. 
El horror a la autocracia imperial, que iba a derrocar una constitución que por espacio de tantos siglos había sido el orgullo y la fuerza de los romanos, que iba a sellar para siempre la urna electoral en los comicios, a imponer un silencio de muerte a los Rostros, desde cuya altura la voz omnipotente de Roma se hacía oír hasta los últimos confines del mundo, que iba en fin a sustituir a la voluntad de un gran pueblo el capricho de un tirano: este horror legítimo en quien se sentía el primer hombre de estado de su siglo y el más grande orador de su patria, lanzó a Cicerón a los campos de Farsalia. Después de la vergonzosa derrota de Pompeyo, vencido en aquella famosa jornada sin haber combatido, humillado por el altivo perdón que le concede el vencedor, la vida política del ilustre orador parece terminada para siempre. (Camús, apud Menéndez Pelayo, 1952: 410-412).

Hasta aquí, Camús describe a Cicerón en los términos esperables de un pensador liberal influido por las lecturas del siglo XVIII. Sin embargo, sorprende cómo Camús analiza el nuevo papel que cobra Cicerón cuando esa lucha por la libertad ya está perdida ante la autocracia cesariana. Así es como surge, al final de su vida, el Cicerón que implora el perdón de los vencidos:

Sin embargo, aquí empieza una de las páginas más interesantes y tiernas de Marco Tulio, y que, como yo extrañaba hace poco, no habían señalado bastante cuantos han tratado de escribir la vida de tan grande varón. Desde este momento su voz elocuente, que no volverá a vibrar en defensa de la libertad que ha muerto para no resucitar jamás, se alzará en adelante para implorar del dictador el perdón de los vencidos, para demandar la vuelta a la patria de tantos nobles ciudadanos, que lloran en tierras extrañas la muerte de sus amigos y parientes, la pérdida de sus haciendas confiscadas, la ruina de sus casas (Camús, apud Menéndez Pelayo, 1952: 410-412).

Es esa actitud, que Camús considera "una de las páginas más interesantes y tiernas de Marco Tulio", la que lleva al viejo orador republicano a defender valientemente la vida de Quinto Ligario, sobre todo cuando se parte del hecho probado de que éste es culpable:

[...] intenta Cicerón la defensa de Quinto Ligario a instancias de su familia, Pansa y otros varios senadores. Pero el dictador que se había manifestado clemente para con los que habían combatido en Farsalia por Pompeyo, permanecía inflexible para con aquellos que se habían 
unido con Metelo, Escipión, Varo y Iuba, Rey de Mauritania, para hacerle la guerra en África. Cuantas súplicas privadas se le habían dirigido habían quedado sin respuesta, cuando Tuberón, enemigo personal de Ligario, por sugestión quizás del mismo dictador le acusa públicamente en las formas ordinarias de haber encendido la guerra en África, y lo denuncia como culpable de traición y reo de estado. Acuerda César que esta causa se decida en el foro, reservándose el derecho de pronunciar la sentencia. La elocuencia de Cicerón arrancó del dictador la gracia de uno de sus más odiados enemigos: el discurso religiosamente copiado por los taquígrafos, fue publicado inmediatamente, y su primer traslado quiso conservarlo el dictador para leerlo y meditarlo a solas.

Fue pronunciada esta célebre oración a fines del año 707 cuando Cicerón contaba sesenta y uno de edad, esto es, tres antes de su desastrada muerte a manos de los sicarios de Antonio y de la hermosa Fulvia su mujer, de aquella tigre sin vergüenza y sin entrañas, que se entretuvo, dice la historia, en picar con la aguja de oro de su tocado la yerta lengua de aquella ensangrentada cabeza, que clavada en los Rostros que tantas veces había iluminado con palabra soberana, parecía recordar a los romanos la libertad perdida en las saturnales del Triunvirato (Camús, apud Menéndez Pelayo, 1952: 410-412).

Este Cicerón trágico, no exento de sublime patetismo, en quien podemos adivinar los tintes románticos de un héroe ante las causas perdidas, es el producto de su relectura en una nueva época, la segunda mitad del siglo XIX. Es encomiable de qué manera Camús ha llevado a cabo un intenso salto en la historia que va desde Cicerón y su defensa a Ligario, en el trasiego de las luchas políticas romanas, hasta el turbulento contexto político de la España de los años 50 del siglo XIX, pasando por la propia Ilustración hispana, para mostrar una visión liberal y romántica del autor latino.

\section{Conclusiones}

Analizados los distintos aspectos de la obra de Camús dedicada al Pro Ligario ciceroniano, cabe preguntarse, finalmente, qué significa la ficción traductora que encontramos en ella. Consideramos que esta traducción ficticia, atribuida a un ilustrado de tiempos de Carlos III y hallada en un manuscrito dentro de unas circunstancias novelescas y dramáticas, no deja de ser uno de los elementos clave con los que Camús construye su particular lectura liberal (a partir de Middleton) y romántica de 
Cicerón. La lectura liberal nos ofrece a un Cicerón amante de la libertad de la república, pero, una vez perdida para siempre esta libertad bajo el poder absoluto de César, tan sólo queda ya rogar su clemencia a favor de los ciudadanos que lucharon por su patria, aunque en el bando contrario. La traducción ficticia no deja de ser una forma de hacer hablar a Cicerón a través de la Historia, desde su propia circunstancia en los convulsos tiempos del final de la república, pasando por la herencia ilustrada de una España que pudo ser y no fue, y llegando, finalmente, hasta los no menos convulsos y contemporáneos tiempos de Narváez y O'Donnell, donde la lucha por la libertad y la necesidad de clemencia siguen estando tan vivas como en los tiempos de César.

\section{Bibliografía}

Aradra Sánchez, Rosa María. 2011. Cicerón ilustrado. La recepción de su obra en la retórica española del siglo XVIII. Revista de Estudios Latinos 11: 185-205.

Bermejo, Ildefonso Antonio. 1872. La estafeta de Palacio (Historia del último reinado). Cartas trascendentales dedicadas A.S.A.R. el príncipe D. Alfonso de Borbón, Tomo tercero. Madrid: Imprenta de R. Labajos.

Camús, Alfredo Adolfo. 1847. Curso elemental de Retórica y Poética: Retórica de Hugo Blair, Poética de Sánchez, Madrid: Imp. de La Publicidad, a cargo de M. Rivadeneyra.

Camús, Alfredo Adolfo. 1857a. Epístola a Don Manuel de Assas. Semanario Pintoresco Español: 30-31; publicada también en La discusión, 5 de marzo de 1857: 3 .

Camús, Alfredo Adolfo. 1857b. Oración de Cicerón a César por Ligario, traducida por D. Francisco Carrasco, marqués de la Corona, oidor de la Audiencia de Zaragoza y fiscal del Supremo Consejo de Hacienda en tiempo de Carlos III. Semanario Pintoresco Español: 37-40.

Camús, Alfredo Adolfo. 2015. Carta a don Emilio Castelar. Edición y estudio introductorio de María José Barrios Castro y Francisco García Jurado. Madrid: Escolar y Mayo.

Cicerón. 1789. Oraciones Escogidas de M. T. Cicerón en latín y castellano, Madrid: Antonio de Sancha, 2 vols. (ediciones posteriores: Barcelona: Imp. de Sastres, 1808, 2 vols; Barcelona: Imp. de Sierra y Martí, 1829; París: Librería de Rosa, 1836 y París: Libr. de Rosa y Bouret, 1854).

Cicerón. 1970. M. Tulli Ciceronis Orationes. Pro Milone. Pro Marcello. Pro Ligario. Pro Rege Deiotaro. Philippicae I-XIV. Recognovit brevique adnotatione critia instruxit Albertus Curtis Clark, Oxonii: E typographeo Claredoniano. 
Cicerón. 2011. Discursos VII, trad. José María Requejo. Madrid: Gredos. Delgado Barrado, José Miguel. 2005. De fiscal a escritor político. El caso de Francisco Carrasco de la Torre, Marqués de La Corona, Fiscal del Consejo de Hacienda (1715-1791). En Aranda Pérez, Francisco José (coord.) Letrados, juristas y burócratas en la España moderna. Cuenca: Ediciones de la Universidad de Castilla-La Mancha, 515-534.

Friera Álvarez, Marta. 2007. La desamortización de la propiedad de la tierra en el tránsito del antiguo régimen al liberalismo (la desamortización de Carlos IV). Gijón: Caja Rural.

García Jurado, Francisco. 2002. Alfredo Adolfo Camús. Madrid: Ediciones Clásicas.

Martínez Villergas, Juan. 1851. Paralelo entre la vida militar de Espartero y la de Narváez. Obra interesante por su objeto, útil para los que quieran saber a punto fijo las hazañas de los expresados generales, y necesaria a los que fascinados por el brillo de la exterioridad hayan creido ver más que un héroe donde apenas hay un hombre. Madrid: Imprenta de J. Antonio Ortigosa.

Mayans i Siscar, Gregorio. 1786. Rhetorica. Valencia: Por Josef i Thomas de Orga.

Menéndez Pelayo, Marcelino. 1952. Bibliografía Hispano-Latina Clásica II. Santander: Aldus.

Middleton, Conyers. [1790] 1804. Historia de la vida de Marco Tulio Cicerón escrita en inglés por Conyers Middleton bibliotecario general de la Universidad de Cambridge; traducida por el Exc. Sr. D. Josef Nicolás de Azara. Segunda edición. Madrid: En la Imprenta Real.

Moxó y Ortiz de Villajos, Salvador. 1959. "Un medievalista en el Consejo de Hacienda. Don Francisco Carrasco. Marqués de la Corona (17151791). Anuario de historia del derecho español 29: 609-668.

Nisard, Désiré. 1840. Oeuvres complètes de Cicéron avec la traduction en Français publiées sous la direction de M. Nisard. Tome troisième. Paris: J.J. Dubochet et Compagnie.

Palau y Dulcet, Antonio. 1935. Memorias de un librero catalán: 1867-1935. Barcelona: Librería Catalonia.

Sánchez Espinosa, Gabriel. 1999. José Nicolás de Azara, traductor: la Historia de la vida de Marco Tulio Cicerón de Conyers Middleton. En Lafarga, Francisco (ed.) La traducción en España (1750-1830). Lengua, literatura, cultura. Lleida: Edicions de la Universitat de Lleida, 285-296.

Simón Díaz, José. 1946. Semanario pintoresco español (Madrid, 1836-1857). Madrid: Instituto "Nicolás Antonio" del Consejo Superior de Investigaciones Científicas (Alicante: Biblioteca Virtual Miguel de Cervantes, 2012). 